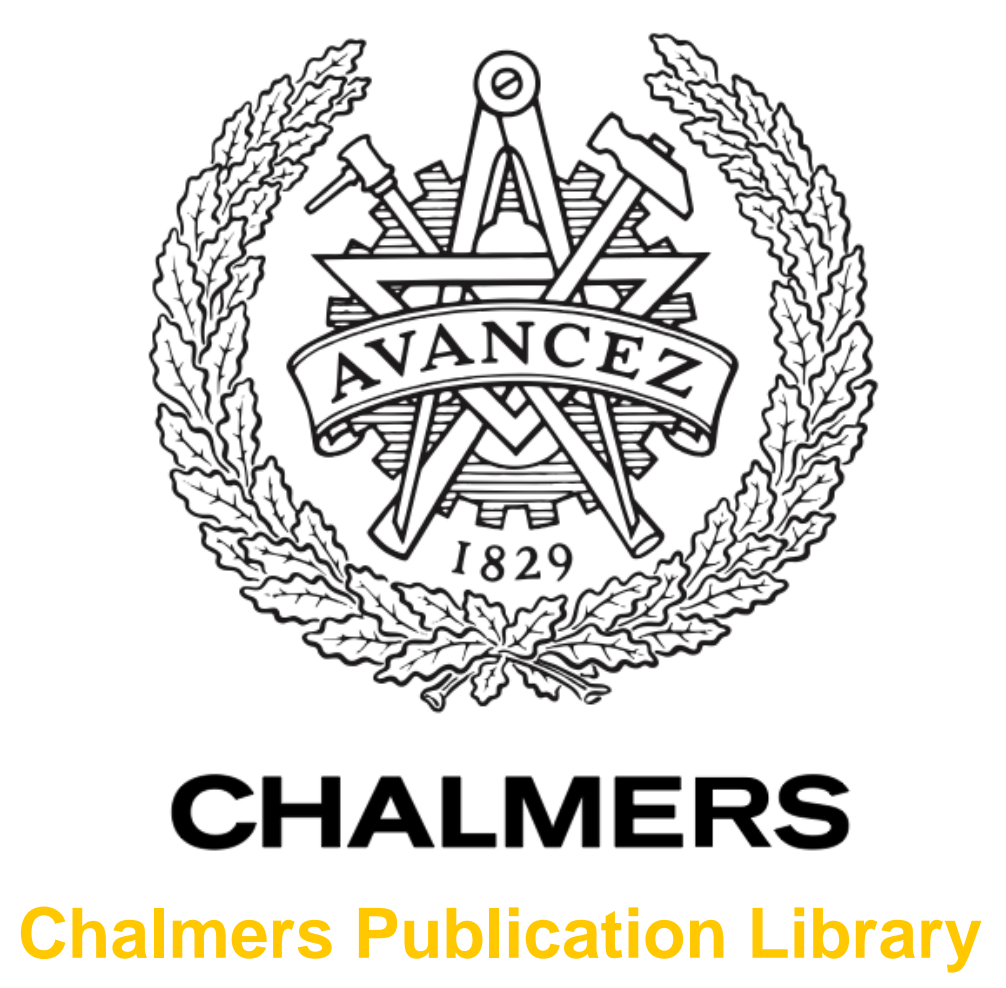

\title{
Knowledge sharing and learning across community boundaries in an arena for energy efficient building
}

This document has been downloaded from Chalmers Publication Library (CPL). It is the author's version of a work that was accepted for publication in:

Journal of Cleaner Production (ISSN: 0959-6526)

Citation for the published paper:

Gluch, P. ; Johansson, K. ; Räisänen, C. (2013) "Knowledge sharing and learning across community boundaries in an arena for energy efficient building". Journal of Cleaner

Production, vol. 48(June 2013), pp. 232-240.

http://dx.doi.org/10.1016/j.jclepro.2012.10.020

Downloaded from: http://publications.lib.chalmers.se/publication/166864

Notice: Changes introduced as a result of publishing processes such as copy-editing and formatting may not be reflected in this document. For a definitive version of this work, please refer to the published source. Please note that access to the published version might require a subscription. 


\title{
KNOWLEDGE SHARING AND LEARNING ACROSS COMMUNITY BOUNDARIES IN AN ARENA FOR ENERGY EFFICIENT BUILDINGS
}

\author{
Pernilla Gluch, Associate Professor, Ph.D. \\ pernilla.gluch@chalmers.se,+46-(0)31-772 1961 \\ Karin Johansson, M. Sc., Lic. Eng. (corresponding author) \\ karin.johansson@chalmers.se,+46-(0)31-772 2237 \\ Christine Räisänen, Professor, Ph.D. \\ christine.raisanen@chalmers.se,+46-(0)31-772 1950
}

Div. of Construction Management, Dep. of Civil and Environmental Engineering, Chalmers University of Technology, SE-41296 Göteborg, Sweden

\begin{abstract}
Within the field of sustainable development, collaborative and interdisciplinary actions are imperative for the development and implementation of proactive holistic renovation solutions. In an attempt to enhance cross-disciplinary and inter-organisational knowledge sharing, a project aimed at developing an arena for sharing knowledge pertaining to energy-efficient renovations of multi-family buildings was initiated. The authors have followed the development and implementation of this knowledge arena over a period of three years. The aim of this paper is to understand how knowledge sharing between different professional groups and practices may be facilitated: in this case between various research organisations, municipal housing companies, energy suppliers and governmental organisations. Specific focus has been on identifying mechanisms for interaction and knowledge sharing between actors that normally do not meet in their everyday practice. The theoretical approach adopted concerns social processes related to the sharing of knowledge in and between organisations and professional groups and individuals. Findings show that in the arena knowledge was mainly shared within a pilot project where researchers and practitioners were jointly engaged in the planning and renovation of a building. Interaction within the arena was enabled by the individuals' mutual willingness to adapt and attempt to translate the disciplinary discourses and modes of communication of researchers and of practitioner specialists. Moreover, the motivation to share knowledge was related to their expectations of, and invested interest in, various arena activities. By empirically highlighting the facilitators and hindrances for knowledge-sharing in an arena for cleaner production, the paper contributes to increased understanding of inter-disciplinary communication and collaborative interaction.
\end{abstract}

Keywords: energy efficiency, inter-organisational learning, knowledge sharing, mediating objects, renovation of residential housing 


\section{Introduction}

The Swedish parliament has set the target of a $50 \%$ reduction of energy use in buildings by 2050. To meet this target all existing buildings have to be replaced by new ones, or be renovated to attain the same energy performance as new buildings (Dalenbäck and Mjörnell, 2011). Today, a majority of the multi-family buildings built between 1965 and 1975 are in imminent need of extensive renovation as a result of many years' neglected maintenance. These buildings are largely owned by public housing companies and comprise approx. 600.000 apartments, with an average energy consumption of $185 \mathrm{kWh} / \mathrm{m} 2 /$ year. The regulated demand is at present $110 \mathrm{kWh} / \mathrm{m} 2 /$ year for new buildings (Swedish Energy Agency, 2011). How to address this challenge is currently a much debated issue among researchers, practitioners and policy makers. One point of agreement among the parties is that to meet the challenge of reducing the energy consumption of buildings, reliable knowledge must inform the planning, building and operating of sustainable residential housing.

Over the last decade, the construction industry in Sweden has invested much effort into developing green technology (e.g. low energy buildings) and implementing various control systems (e.g. classifications) to make buildings energy efficient (Malmqvist et al., 2011; Swedish National Board of Housing Building and Planning, 2010; Thuvander et al., 2011; Toller et al., 2011). In line with other countries, this development has been driven by governmental regulation and policies, self-regulation activities (through standards such as ISO14001, LEED) and R\&D collaborations between industry and research institutions (e.g. E2ReBuild, 2012; Lågan, 2012; Tofield and Ingham, 2012;). One such initiative was launched in 2007 when the governmental Swedish Energy Agency instituted a grant aimed at stimulating R\&D initiatives for sustainable renovation of apartment buildings (Cerbof, 2011). This incentive served as grounds for the creation of a 'network project' with the articulated ambition to create interaction and share knowledge between actors engaged in energy efficiency and renovation endeavours (Dalenbäck and Mjörnell, 2011).

What was to later be called a 'knowledge arena' was thus initiated in 2008 as a means of creating a meeting place for joint activities and discussions on issues related to energy efficient renovation of multi-family housing. The interaction within the arena was intended to evolve around ongoing pilot projects, open arena seminars and meetings. The objective of the knowledge arena was to share existing knowledge as well as create new knowledge pertaining to the framework for energy renovation of multi-family buildings (Dalenbäck and Mjörnell, 2011). The anticipated contributions of this network project were: 1) to increase knowledge sharing between the participating researchers and practitioners, e.g. real estate owners and building contractors, 2) to facilitate the mediation of practical knowledge from ongoing projects to researchers, and 3) to disseminate this knowledge to other and future projects. These prospective contributions seem to reflect the underlying assumption that knowledge is created and exchanged when people from various knowledge fields meet and interact around a shared interest and/or task. However, much due to the projectified, multidisciplinary and fragmented nature of the construction industry, creating common spaces for reflection and knowledge sharing is difficult to accomplish. Moreover, empirical evidence for the assumption remains elusive (Bresnen et al., 2005; Dainty et al., 2006; Dubois and Gadde, 2002).

Yet within the field of sustainable development, collaborative and interdisciplinary actions have been found to be crucial for the development and implementation of proactive, holistic and innovative green solutions (Brown et al., 2003; Vergragt and Brown, 2007; Quist et al., 2011). The same applies to the field of energy-efficient building (e.g. Brown and Vergragt, 
2008; Cole, 2011; Glad, 2012; Heiskanen and Lovio, 2010). For example, Cole (2011) concluded that there is a lack of understanding of the social and organisational interplay amongst and between different stakeholders involved in sustainable building. Whyte and Sexton (2011) substantiated this lack, by calling for research that specifically addresses stakeholder engagement in the transformation of the built environment.

In line with their call the aim of this paper is to further the understanding on how knowledge sharing between different professional groups and practices may be facilitated: in this case between various research organisations, municipal-housing companies, energy suppliers and governmental organisations. To fulfil this aim, we have followed the development and implementation of the above mentioned knowledge arena for energy efficient renovation of buildings over a period of three years (August 2007 - May 2010). Specific focus has been on identifying interactions and knowledge-sharing processes/activities between actors that normally do not meet in their everyday practices.

The paper is structured as follows: In section 2, the theoretical framing drawing on sociocultural perspectives of knowledge creating and sharing is presented and discussed. Section 3 describes the research approach and analytical procedure. In section 4, the case study is elaborated and the findings are reported and discussed under thematic sub-sections. The three first sub-sections correspond to the three interview themes, and the fourth sub-section deals with the mediating tools used by the respondents and observed by the researchers to enhance interaction and knowledge sharing. Sections 5 and 6, respectively, discuss the implications of the findings for future inter-organizational knowledge-sharing endeavours and conclude the paper.

\section{Theoretical frame: Knowledge sharing in communities of practice}

The study reported here is framed by a socio-cultural view, in which learning and knowing, are dynamic activities that take place in situated contexts and practices (e.g. Lave and Wenger, 1991; Gherardi and Nicolini, 2000). Seen from this perspective, knowledge is not a decontextualised abstraction that is transferred from one individual to another and stored in a knowledge repository to be accessed when needed; rather it is embedded in the processes, methods and tools of a practice as well as in the people that carry out the practice (Gherardi and Nicolini, 2000). Practice is viewed as some kind of institutionalised 'doing', which has been socially and culturally constructed through a social system of relations, where agency may be distributed between individuals and artefacts. Practice, in the same way as learning and knowing, is emergent, consisting of collective and situational activities that take place through interconnected people in a group, community or network (Heiskanen et al., 2010; Gherardi and Nicolini, 2000; Gluch and Räisänen, 2009; Gheradi, 2009). Thus, meaningful learning and knowing takes place when individuals collectively engage in practices in which they have a strong commitment or vested interest, e.g. in a community of practice, CoP (e.g. Wenger, 1998). It is in these practices that information may be exchanged and knowledge may be shaped and shared. In such a relational shaping process, notions of, for example, energy efficiency and climate change may be verbalised in the discourse of a particular party, but these notions also need to be translated into the relevant discourses of other parties before the notions may be appropriated and made sense of by all parties (Füssel, 2005; Stenberg and Räisänen, 2006).

Elements of the CoP perspective on learning are relevant for a study of the shaping of a knowledge arena: individuals actively engaging in an area of concern (domain) form a community focused on growing the domain through group and individual meaning-making in 
a situated, relevant collective practice (Wenger, 1998). Brown and Duguid (2001:200) suggest that it would be "fruitful to look to the context in which knowledge sticks or leaks". In areas where there are distinct fields of knowledge, for instance in development and innovation processes for low-energy housing, knowledge seems to get stuck within particular fields. It is much more difficult to diffuse and share it beyond the fields' boundaries (e.g. Heiskanen and Lovio, 2010). The challenge for researchers and practitioners with interests in the same domain, but inhabiting different fields is finding ways of making community boundaries sufficiently plastic to allow knowledge sharing.

A particularly interesting aspect of CoPs is that they develop shared repertoires of routines and semiotic and technical mediating tools that shape their identity (Räisänen, 1999). It is thus through their practices that a CoPs can be identified. The interpretation and use of a shared repertoire also discloses a CoP's boundaries to another. Although CoPs are far from discrete and isolated entities, they often tend to be viewed as such (Brown and Duguid, 2001). This may be because the knowledge that a community possesses reflects its norms and preoccupations and, in the long run, limits its ability to develop new ideas (Kimble et al., 2010).

Today boundary-crossing activities for accessing information from outside a group are becoming increasingly important in interdisciplinary and fragmented industries such as construction. Knowledge sharing across community boundaries can, according to Teigland and Wasko (2003), be facilitated through participation in social networks, informal meetings and workgroups. Furthermore, governing entities may act as enablers for knowledge sharing across community boundaries by mobilising incentives for collaborative endeavours and mutual engagement to solve societal or organisational problems (Brown and Duguid, 2001). To achieve mutual engagement across community boundaries, proactive attention needs to be focused on practice, interaction and participation since interaction between individuals arise from their mutual engagement in practice and not from an idealised view of what a community should be (Heiskanen et al., 2010). Moreover, based on a study of a zero-energy residential building project, Brown and Vergragt (2008) concluded that higher order learning within a project community was stimulated when there were overlaps of the interpretive frameworks and practices held by the participants, such as developer, urban planner, architect and energy analyst. To stimulate learning in boundary-crossing communities means supporting activities where overlapping practices can meet so that the framework is expanded and in turn can foster cross-fertilization between professional communities.

In interdisciplinary and boundary-crossing communities, it is important to pay attention to how engagement and knowledge sharing within communities evolve. CoPs develop over time when the members collectively begin to act as member of the community and not merely as representatives of their other communities and commitments (Heiskanen et al., 2010). To facilitate appropriation of information and knowledge in an interdisciplinary community requires competent mediators such as boundary brokers who can translate the jargon of one field into that of another. The community also needs effective, preferably co-constructed mediation tools (semiotic and technical) which are acknowledged and understood by the different groups of members (Brown and Vergragt, 2008). It is therefore critical to consider what artefacts may serve as mediating representations and what challenges may arise when attempting to align divergent interests (Gluch and Räisänen, 2012; Heiskanen et al., 2010). It is with these issues in mind that we have used the concept of $\mathrm{CoP}$ as a point of departure in our study of the energy-efficiency arena. 


\section{Research approach}

The empirical data were gathered using different qualitative methods: observations, interviews and document analysis. Over a period of three years (August 2007 - May 2010) the following events were observed: two workshops at the initial stage of the arena project, then five planning meetings, two open seminars, one reference-group meeting, two company presentations which included construction-site visits, and lastly three site meetings of a pilot project within the arena. Extensive field notes covering formal and informal interactions, talk and body language provided a contextual understanding, which helped us make sense of the ensuing interviews (Bryman, 2008).

In the spring of 2010, 18 interviews lasting between 1 to 3 hours were carried out. The interviewees were selected from the arena's contact list of 50 individuals, ensuring all participating organisations were represented. All the interviews were recorded. The interviewees were divided into two groups: researchers (8 interviewees: R1-8) and practitioners (10 interviewees: P1-10). R1-8 were employed either at a Technical University (TU) or at a Research Institute (RI). Interviewees employed within municipal housing companies, a local energy company and the local governing authority made up the P1-10 group. We, the authors, were positioned as academic observers trying to understand and interpret the dynamics of the arena, with as little direct participation as possible.

The interviewees were encouraged to elaborate freely on three themes informed by the theoretical frame: 1) energy-efficient renovation as a field of knowledge, 2) their personal engagement and knowledge sharing in the arena project, and 3) their own organisation's views on its taking part in the arena. The interviewees were asked to exemplify where, how and when they perceived that knowledge was being shared i.e. in what particular circumstances. They were also asked about their perceived possibilities of sharing any newly acquired knowledge within and across their own professional community boundaries. Respondents were asked to draw a map of their communication paths within the arena and identify the issues they communicated about, the medium they used (e-mail, telephone, informal or formal meetings), and how often they communicated.

For the purpose of this paper, a content analysis (Salkie, 1995) of the interviews was carried out focusing on the interviewees' perceptions and stories concerning the three themes. The interviews were listened to and summarised iteratively, resulting in a detailed list of quotes, phrases, concepts and key words pertaining to the themes in focus. The detailed summaries were then further analysed to compile representative stories, depicting the different views and attitudes toward arena activities and events. To minimise researcher bias, each author processed the data separately and then compared interpretations. The few discrepancies that arose were resolved through dialogue. The interviewees' personal contact maps were analysed to identify common communication paths. Documents produced within the arena, such as meeting protocols, information leaflets and seminar material, were analysed and served as background information.

\section{Findings: Arena for energy efficient renovation of buildings}

The initiative to create a knowledge-sharing arena can be ascribed to a few researchers from a Technical University and a Research Institute. A professor in building energy technology took on the role of self-assigned arena leader without any apparent resistance from the others. Together, these researchers successfully applied for the state-instituted Energy Agency grant for the development of a knowledge arena in collaboration with interested municipal housing 
companies. The arena objectives, as formulated in the application, was three-fold: 1) to share knowledge between researchers and practitioners (clients, contractors and consultants), 2) for researchers to gain knowledge from real-life projects and, 3) to disseminate this knowledge to future projects. A dominant idea was that participants in the forum would create and share knowledge by interacting with each other in common forums where particular and relevant mediating objects and tools would be used. These objectives reflect the assumption that knowledge is exchanged when people from different knowledge fields within a general domain meet and interact around a shared interest and/or task.

Since the domain of the arena was renovation of multi-family housing, local authorities, housing companies and energy suppliers were solicited to join forces with the researchers to develop the arena. Altogether, six municipal housing companies, one local energy company and the local governing authority were co-opted as partners in the shaping of the arena community. Each partner was assigned an account on which it could draw to fund consultants within those areas in which they lacked expertise, e.g. business operations and quality testing of technical solutions in climate laboratories. Notable in this arena context was that hardly any of the participating entities made use of this possibility.

\subsection{Perceptions of energy-efficient renovation as a knowledge domain}

Table 1 presents the findings from the analysis of theme one in the interviews. It shows how the two groups, R1-8 and P1-10, described energy-efficient renovation of buildings.

The researchers talked of energy efficiency in housing as a concern that implicated society as a whole, both current and future generations, and must therefore be dealt with in a long-term perspective. For them, particular technical solutions only marginally impacted the societal imperative of developing sustainable energy consumption. In their view, energy-efficient renovation can only be fully achieved through a socio-technical approach, involving the collaboration of actors at various levels and spheres of society and using a variety of integrated technologies and artefacts, as the quote illustrates:

It is not in the advanced technology, and by that I mean material development or advanced installations, but in the interaction and the discussion, a sensible discussion between for example the architects and the engineers (R6).

Table 1. How energy-efficient renovation of buildings was framed by the interviewees

\begin{tabular}{|l|l|l|}
\hline & Researchers & Practitioners \\
\hline Scope & Integrated on a societal level & $\begin{array}{l}\text { Limited to local interest within a specific } \\
\text { type of business organisation or renovation } \\
\text { project } \\
\text { Short term (now - 2 years forward) }\end{array}$ \\
\hline $\begin{array}{l}\text { Technical } \\
\text { frame }\end{array}$ & $\begin{array}{l}\text { A systems approach in which change } \\
\text { toward energy-efficient renovation of } \\
\text { buildings lies in the managing of system } \\
\text { structures. } \\
\text { Knowledge needs to be disseminated }\end{array}$ & $\begin{array}{l}\text { A practice-oriented approach in which } \\
\text { energy-efficient renovation of buildings } \\
\text { lies in fine-tuning existing systems and } \\
\text { changing technical details } \\
\text { Knowledge is acquired }\end{array}$ \\
\hline $\begin{array}{l}\text { Problem } \\
\text { solving } \\
\text { approach }\end{array}$ & $\begin{array}{l}\text { To influence system structures through } \\
\text { full-scale socio-technical experiments } \\
\text { (pilot projects) } \\
\text { Peer collaboration and practitioner } \\
\text { participation }\end{array}$ & $\begin{array}{l}\text { To influence practice by identifying } \\
\text { technical solutions through one-off } \\
\text { development projects (pilot projects) } \\
\text { Interaction with peers to indentify best } \\
\text { practices }\end{array}$ \\
\hline
\end{tabular}




\begin{tabular}{|l|l|l|}
\hline & Provide normative guidelines & Use of tools \\
\hline $\begin{array}{l}\text { Conceptual } \\
\text { frames }\end{array}$ & $\begin{array}{l}\text { Zero-energy, passive housing, } \\
\text { sustainable solutions, socio-technical } \\
\text { approach, societal values }\end{array}$ & $\begin{array}{l}\text { Reduce energy use per m² } \\
\text { technical solutions, performance, } \\
\text { return on investment }\end{array}$ \\
\hline
\end{tabular}

The researchers claimed that the change towards energy-efficient housing lies in the handling of system structures, i.e. the way technical structures and/or society is able to support change toward using less energy, energy reuse and small-scale production of 'clean' energy such as solar panels and waste energy delivered to the grid. In order to be able to influence system structures and systems thinking, researchers preferred working in pilot projects (full-scale socio-technical experiments) in collaboration with other researchers and with industrial partners (practitioners). They also tended toward a normative and prescriptive research ideology to influence and underpin regulatory measures to support funding of large-scale development of energy technology. They saw themselves as the propagators of research-based knowledge beyond their own institutes to professional and practitioner communities. In this way they perceived that they contributed to societal and technological change. The discourse of the researchers tended to be couched in abstract concepts and technical jargon, e.g. passive housing, and their discourse was oriented toward future possibilities rather than day-to-day problems.

The practitioners reflected a short-term perspective on energy-efficient renovation of buildings, which some argued to be a result of their organisation's predominant concern for financial value, revenues and return-on-investments. This limited time perspective framed their view of energy efficiency as well as constrained their possibilities to argue for long-term investments in their day-to-day practices:

What is really difficult to discuss in the company is saving over several years from now. These [future savings] have no value today (P4).

In the same way as for the researchers, pilot projects focused on energy efficiency were important for the practitioners, especially development projects carried out in their own organisations. These served as reference objects when communicating and explaining the concept of energy-efficient renovation. The practitioners tended to have a practice-oriented approach, in which energy-efficient renovation consisted mostly of fine-tuning existing systems and improving technical details. Key terms frequently used when explaining the notion of energy-efficient renovation were technical solution, reduced energy use and return on investment, which reflected a pragmatic mindset oriented toward the present. For them, knowledge was a commodity, something to be acquired through cooperating with others, mainly their fellow practitioners.

Some of the practitioners were frustrated with the constraints imposed on them by their organisation's limited attitudes to energy efficiency and the lack of long-term commitment regarding social, environmental, and economic sustainability. What these practitioners had in common was a strong personal interest and commitment to sustainability issues. There were also some divergent views, within the group of researchers concerning energy-efficient renovation. Some demonstrated a broad societal interest and commitment while others seemed to be solidly entrenched in their specific field of technological expertise. These different outlooks within the same group gave rise to alliances across research/practitioner boundaries, but also to tensions. 


\subsection{Reasons for engagement in arena activities}

From the interviews, the underlying motivation for the arena was a belief among researchers that practitioners needed expert knowledge to effectively take on the challenges of reducing energy use in building renovation. Therefore the researchers voiced irritation that many practitioners from municipal-housing companies hesitated to take active part in the knowledge arena. This was perceived by the researchers as lack of interest and even lack of concern for energy efficient-buildings.

We have to chase people to make them show an interest, to find those who want to be engaged and involved [in the arena] (R3).

This quote reflects some of the frustration among the researchers at the practitioners' lack of immediate involvement in what the researchers implicitly considered an initiative for the benefit of the practitioners. Conversely, most practitioners initially experienced the arena as a forum for the researchers rather than for joint activities and sharing of knowledge between researchers and practitioners. Even though interest in the arena gradually increased, the motivation was often ambiguous, such as being obliged to attend since their organisations was financial committed to the arena project; or having to stand in for a colleague. Yet others felt that participation was required by their professional role and consistent with their duties within their own organisation. These could be reasons why the arena seminars were well attended, while there was little interest in the other joint activities. Other practitioners, who did have personal interests in energy-efficient renovation, were forced to de-prioritise this domain and the opportunities that the arena availed them due to their organisation's lack of interest.

Among the researchers, the reasons for participating in arena activities were more consistent. Many identified with the formulated ambitions of the arena. They sought opportunities to initiate pilot projects with practitioners and elicit feedback from these, on their research. They also saw themselves as repositories and disseminators of new knowledge to practice. The researcher group in the forum grew from an initial handful to 21 researchers, including fields such as installation engineering, building-energy technology, building physics, indoor climate, construction management, and architecture. Contrary to the practitioner group, the researchers shared a history as well as belonging to an umbrella scientific sub-community. Many had collaborated on research projects and were university colleagues or former fellow-students. Thus, the arena partly consisted of an already established researcher's network. These factors as well as the strong convictions manifested in the researchers' ways of expressing themselves could explain the practitioners' perceptions of the arena as predominantly a forum initiated by researchers for researchers. Reinforcing the practitioners' perception, was the lack of formal roles and hierarchical structures within the arena, i.e. the members participated as professional equals within their specific fields with equal opportunities to become involved and interact within the arena framework. For practitioners, this rather typical academic implicit structure could have generated impressions of lack of structure.

\subsection{Joint activities for knowledge sharing}

As formulated in the arena-project aims, joint activities formed the springboard for knowledge exchange between researchers and practitioners. These joint activities were pilot projects initiated by the practitioners, open seminars and arena meetings. Two arena pilot projects were carried out within the arena, of which the first was launched at the same time as the arena in 2007 (hereafter called the pilot project). The second was launched in 2010 and only 
briefly dealt with in this article. Two arena seminars and numerous meetings in various constellations took place during the duration of this study.

Related to the pilot project, a workshop to discuss possible technical solutions' effects on the building exterior and on energy efficiency was held. The interviewees that had participated in this workshop had positive experiences of the activity. A critical factor for the success was the possibility of meeting face-to-face and spending time discussing one issue and its ramifications at length. Many researchers and practitioners found participating in the pilot projects self-developing. The researchers had been eager to collaborate both with each other and with practitioners in order to learn more from real-life situations. Practitioners felt that they had learnt from collaborating with the researchers on the pilot project, and that their membership in the arena community enabled them to test and evaluate technical solutions on site. The pilot project thus offered a space where individuals that had not been in contact before could interact. Through this interaction, researchers and practitioners gradually developed a common vocabulary which allowed them to contribute with their individual bits to 'the puzzle' as a whole. As a result the pilot project stimulated the creation of aggregated ideas for addressing the challenge of making buildings more energy efficient.

The arena seminars were organised around themes and topics related to problems encountered in the pilot project. The first seminar focused on technical solutions, where the practitioners and researchers involved in the pilot project gave presentations and initiated discussions. This seminar also included a field trip to the pilot project. Many practitioners stated that this first seminar and field trip enabled them to experience first hand what the arena was trying to achieve. They also claimed that they had been able to network with researchers, which they normally had little opportunity to do. These activities, they reported, had whetted their appetite for further and more active participation in the arena. Interviews also showed that practitioners used arena seminars as forums for discussions with peers concerning critical matters such as how to run energy-efficient businesses. The arena thus also became a forum where practitioners could ventilate and obtain support for their frustrations and disillusions or celebrate their successes with like-thinking peers facing similar situations.

The second arena seminar was well visited by both practitioners and researchers. Word had spread after the first seminar, and the topic of the seminar, rent setting to cover increasing costs for energy-efficient renovation, was highly relevant to the practitioners. The interviewees found that this seminar produced a common understanding of how economic cut-backs impacted possibilities of implementing far-reaching actions. Most of the interviewed practitioners stated that they initially participated in the seminars out of curiosity, to find out what other companies were doing within the domain. The interviewed researchers, on the other hand, saw the seminars as opportunities for obtaining information about practitioners' energy-efficiency practices and their perceived obstacles.

The interviews as well as the observations of arena activities indicate that the researchers and practitioners, through their discussions and dialogue, gradually developed a shared understanding of the challenges that needed to be overcome to achieve energy-efficient renovation of housing. Moreover, the arena participants became increasingly aware of the importance of joint activities as a driver of knowledge sharing, which can be corroborated by a stronger interest from municipal-housing companies in initiating pilot projects.

Although the practitioners' interest in the arena slowly increased, the researchers were dissatisfied in the practitioners' lack of active engagement in the activities and in their lack of initiative in availing themselves of the palette of expertise offered. The researchers had 
expected the practitioners to initiate more pilot projects than the two that were realised. For the practitioners, however, starting a pilot project was a cumbersome process; pros and cons, financing, resource allocation and most importantly the benefits for the company needed to be deliberated carefully, all of which are time-consuming activities. For a project with a threeyear funding scheme, time is a scarce resource.

\subsection{Mediators and mediating tools}

Within the arena, a tool for calculating life cycle costs (LCC) was developed jointly by researchers and practitioners working in the pilot project. This tool was used in the pilot project in the selection of products and technical solutions. Interviews showed that the LCCtool in this setting served as a mediating tool during discussions between researchers and practitioners, facilitating knowledge sharing regarding technical solutions to suit energyefficiency demands and economic constraints. Nevertheless, some practitioners perceived that their influence on the design and choice of mediating tools had been limited. They suggested alternative mediating tools, for example an arena web-portal, to enhance communication and knowledge sharing between professional groups within the arena.

The findings indicate that researchers tended to interact mainly with researchers and practitioners with practitioners. This wasted opportunity for cross-disciplinary interaction may be the consequence of different knowledge and information-sharing practices. Researchers stated that they preferred to communicate and mediate information and knowledge through scientific texts and attending academic conferences. This preferred way of sharing knowledge was not that of the practitioners, who stated that they shared knowledge and learned through their day-to-day project practices. Additionally, previously established networks between the researchers rendered interaction between researchers easier than with practitioners.

Figure 1 presents a schematic of typical interaction in the arena, and is based on the analysis of the contact maps (communication paths) that all interviewees drew. The Figure illustrates the positions of the interviewed community members (R1-8, P1-10) within the arena community, as they saw themselves and as others saw them. The closer to the centre, the more influence the members had on activities carried out within the arena. The grey zones illustrate where frequent interaction occurred. One feature that stuck out was the prominent positions of certain individuals, namely the self-appointed leader in the researcher group and the project manager of the pilot project in the practitioner group. These were frequently referred to in all the interviews and seem to have been perceived as "figures of authority". In this respect, they may be seen as the main mediators in the shaping of the arena. 


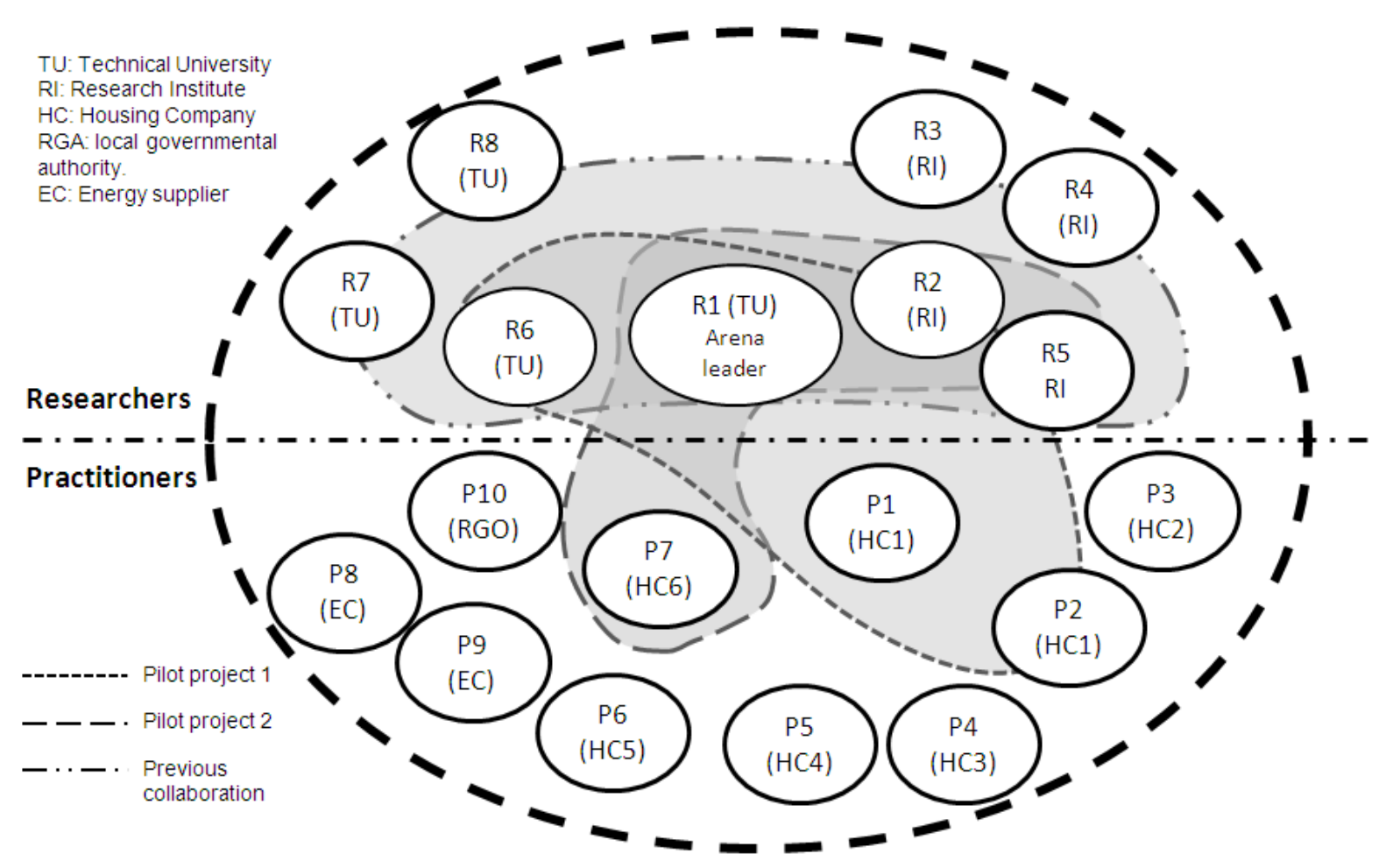

Figure 1: Extensive interaction within the arena community

The leader of the arena, in taking on that role, strongly influenced the framing and scoping of the arena. Reflected in the interviews is the image of an academic with a passionate interest in the subject and a strong belief in the arena project. His mediator sphere of influence, however, was limited to his own community of researchers much due to his inability to translate his vision into a language that the practitioners could readily understand. This is apparent in the interaction patterns (Figure 1), where it can be seen that the researchers mostly interacted amongst themselves, resulting in what can be presumed as an unintentional exclusion of practitioners. The result of this behaviour reified the conventional boundary between research and practice rather than relaxing it.

A second cluster of interaction evolved around the pilot project. Here the manager of the pilot project, a professional with a strong integrity and will as well as a passionate interest in the subject took on the main role of mediator, facilitating knowledge sharing not only in the practitioner group, but across the arena. Words that recurred in all the interviewees' descriptions of her were: enthusiasm, encouraging, and motivating. She also seemed to provide the structure that the practitioners felt they lacked.

It was she who encouraged us, she set up meetings like the workshop, presented a structured agenda and a plan, and it was a good plan. But, also her desire and motivation to do this pilot project. (R6)

As the quote indicates, she also provided structure for the researchers. One explanation for the project leader's effective mediation within and across group boundaries was her sensitivity to the different mindsets and discourses of the two groups. Due to her genuine interest and deep commitment to sustainability and energy-efficient renovation, she sought information in the scientific literature and from researchers, thus learning and internalising their discourse. She was also able to translate research results and implications into a discourse that her peers could easily make sense of and were comfortable with. She was therefore capable of initiating 
dialogue across boundaries. A third cluster of strong interaction was found in relation to the second pilot project, initiated toward the end of our case study, and therefore not within the scope of this paper.

\section{Discussion}

The empirical data describing the shaping of a collaborative platform for knowledge sharing show both successes, such as the initiation of a pilot project, and hindrances such as several participants, both practitioners and researchers, remaining indifferent and inactive in the arena. Through the lens of CoP theory, learning relies on participants' sharing a practice, common interest, visions and goals, engagement and personal vested interest (Wenger, 1998). All these elements were initially present among the researchers, who were able to mobilise a few practitioners as collaborative partners at the grant-proposal stage. However, already at the outset of the development of the arena project, content focus and activities were biased toward a stronger group, the researchers, thus creating tensions that reified conventional boundaries rather than relaxing them. These boundaries were evident in the divergently perceived arena objectives and their framing of energy efficiency as a knowledge domain. For the researchers, the arena objectives were instrumental, prescriptive and normative; for the practitioners they were emergent and principally problem-solving. The researchers had a long-term view on renovation of buildings while the practitioners were constrained by the short-term response to contingencies set by their organisations. In the early phase of the arena project, little strategic effort was spent on the challenges of managing communication and alignment among the inhomogeneous prospective arena members. Instead an ad-hoc trial and error approach was used until one individual was able to take on the role to mediate between the various professional groups. An initial effort to create a common and shared vision of the arena's objectives could have generated stronger participation during the early phase, e.g. by using reflective transition monitoring (Loorbach, 2010), visioning exercises (Vergragt and Brown, 2007) and/or participatory back-casting (Quist et al., 2011); however, such methods were not used.

The arena project's ambition was to create a learning space through strong participation and collaborative interaction among the various professional groups. Yet, the way the arena was designed contradicted this ambition through an adherence to a 'learning by searching' approach based on the logic of the research community (Kamp et al., 2004). This logic is built on a positivist technological paradigm in which a systematic and organised search for knowledge is guided by a (most often) extant theoretical and methodological framework based on pre-existent knowledge and experiments, and for which financing has been allocated. Thus, as propagators for research-based knowledge, the core team of five researchers built the arena in line with what can be seen as a 'science-push' strategy (Kamp et al., 2004). The result, which may be compared to that of the Dutch wind-turbine innovation system explored by Kemp et al. (2004), was a mismatch between the intended role of an arena as a forum where several professional groups can interact and collectively learn from each other and the actual competencies and means in hand to implement these intentions. In spite of the ambition to base knowledge sharing on joint activities, little attention was paid to the actual implications or consequences of the choices of activities. In addition, a deep-rooted assumption among the researchers that practitioners were "in need" of their knowledge created a power imbalance reflected in actors' behaviours, discourses and decisions. As the findings have shown, these conditions are not congenial for building trust and reciprocity.

In the same way as a community of practice (Wenger, 1998), the arena vision was that it would grow from a common strong interest and commitment to sustainable energy-efficient 
renovations. The activities that the arena would design would thus also develop from this common interest. The open seminars hosted through the arena did show potential signs of becoming "drivers for active engagement in the surrounding environment" (Wenger 1998). They offered a space where actors representing a range of interpretive frames and competencies could debate energy-efficient renovation (Vergragt and Brown, 2007). These interactions and exchanges of experience and knowledge were successful in that they led to a gradual development of the arena.

However, creating spaces for knowledge sharing takes time, as does building an arena or a CoP. Some people drop out while others join, which means that the 'drivers' of an arena need to have sufficient space and fulfil necessary conditions if they are to stimulate an interactive innovation process (Loorbach, 2010). One critical condition is time! The three years allotted to the arena project proved too short to develop trust, a common language and understanding to achieve cross-organisational knowledge sharing. In spite of the advantageous preconditions in the form of funding, a perceived need and enthusiastic actors, the creation of an arena community in the form of the initial vision i.e. a driver of sustainability innovation just barely had time to overcome initial difficulties before the projected time span ended. The social interaction that took place within the arena community did not become durable enough to enhance long-term sharing of knowledge to any larger extent.

With a stronger participatory approach (Loorbach, 2010; Quist et al., 2011; Vergragt and Brown, 2007) from the outset, the interaction in the arena might have looked different. Instead, it was not until the pilot project was initiated that interaction between different professional groups occurred to the extent that knowledge could be said to have been shared and appropriated into participants' personal stock of knowledge. It was here that different perspectives met to potentially challenge established, taken-for-granted interpretive frames and practices. Similarly to Kamp et al.'s (2004) study of learning between researchers and practitioners, the pilot project proved to be the most efficient means for knowledge sharing and implementation of energy-efficient technology. Opportunities for learning were facilitated in the pilot project by what Wenger (1998) and Brown and Duguid (2001) refer to as brokering, which the researchers had failed to achieve hitherto. However, the pilot-project manager, through her efforts to align with both researchers and practitioners and her sensitivity to both parties, succeeded in becoming a 'competent' broker or mediator between the two groups (Heiskanen et al., 2010; Wenger, 1998). Her success was largely due to her ability to translate the discourses of the two parties and facilitating communal sensemaking. Once the participants had developed a shared language, dialogue became easier and practical difficulties could be discussed, such as counteracting regulations and cost constraints for energy-efficient renovation in housing. Thus, on the successful side, the arena project came to provide practitioners with a space where they could ventilate and obtain support for their frustrations and disillusions and celebrate successes with like-thinking peers facing similar situations. It also offered an opportunity to discuss these constraints outside the municipalhousing community.

Learning in boundary-crossing communities, such as the arena project, is highly dependent on overlaps in the interpretive frameworks and practices held by the participants (Brown and Vergragt, 2008). This highlights observations made in the study regarding the importance of choosing and/or designing appropriate the mediating tools and artefacts for the purposes at hand (e.g. Bresnen et al. 2003; Räisänen and Linde, 2004). As emphasised by Heiskanen et al. (2010), mediating objects serve an important role within the social construction process in that they help bridge differences in viewpoints thus increasing the potential for cooperation between actors. For example, data concerning the LCC-tool and its use in our study showed 
that it provided practitioners and researchers in the pilot project as well as those within the same municipal-housing company with the same information, which could serve as a common basis for discussions. The LCC tool was shared by cooperating parties and was used as a common referent, even though there may have been differences in particular LCC contents. In this study the LCC tool proved to be an example of a mediating object, which had the capacity to travel across community boundaries (Räisänen and Linde, 2004).

For those who participated in the pilot projects these were perceived the main facilitators for knowledge sharing and learning in the arena. However, many practitioners neither wanted to contribute with nor participate in pilot projects as framed by the researchers. This is most likely a consequence of the researchers' inability to mediate the joint benefits of pilot projects. Instead the practitioners interpreted the pilot projects as reflecting the researchers' own selffulfilment. Their reluctance may also, have been a consequence of the short-term and limited view on energy efficiency of buildings held by the municipal-housing companies. Consequently, the participants' engagement in the arena was limited due to contradictory organisational regimes and practices, such as norms, revenues, return of investments and budget frames. This points to the critical importance of involving top-level managers in such arena endeavours (Quist et al., 2011).

\section{Conclusions}

We conclude that although the arena cannot be fully characterised as a CoP, it did show a potential for facilitating knowledge sharing and learning. It was also found that social interaction around a special interest allows for learning among individuals with various backgrounds. Moreover, collaborative work in small-scale socio-technical experiments, e.g. pilot projects (Brown and Vergragt, 2008; Brown et al., 2003; Kamp et al., 2004) seem to be an efficient strategy to facilitate knowledge sharing and learning across organisational and professional boundaries. However, as we also found, a large number of hindrances arose along the way and had to be overcome e.g. power distance between the groups, different agendas, goals and discourses and different practices. Better knowledge of human behaviour, disciplinary differences and group dynamics as well as proactive design and planning of the arena taking into account risks and possible consequences of choices made could have raised participants awareness and mitigated many of the problems that arose.

This paper has shown that the ways in which information was interpreted and acted upon by arena participants was dependent on the local context, the worldviews as well as also the role, and persuasive force of human mediators to change prevalent interpretive frames (cf. Gluch and Räisänen, 2009). What happened within the pilot project supports the assumption made by Heiskanen et al. (2010) that interrelationships between people arise from engagement in practice and not from an idealised view of what a community should be. Therefore, as argued by Brown and Duguid (2001), for future attempts at creating knowledge-sharing spaces, careful attention needs to be paid to the actual practices within which the knowledge is to be shared, e.g. cleaner production.

In future attempts to stimulate knowledge sharing across professional boundaries in cleaner production, to enhance learning and to improve communication, semiotic tools such as the discourse, genres and platforms need to be adapted to the practices of the communities involved, rather than the other way around. The communication culture and the choice of learning approach as well as mediating tools need to be reflected upon by the actors at an early stage. Moreover, for the realisation of a knowledge arena a self-appointed leader might be necessary, but might not be self-evident once the arena has been launched. Our study 
showed the need to mobilise the "right" partners from the start and to promote the arena in their respectively community using the appropriate discourse. The study also highlights time and space as important factors that need to be considered if interactive innovation processes are sought.

The research approach, where in-depth interviews have been combined with field studies and observations of arena activities, has enabled an opportunity to examine the informality of the interaction and knowledge sharing between different professional groups and practices. In addition, the time-span of the study has created an opportunity to closely follow the development of a collaborative knowledge-sharing forum for energy efficient renovation of buildings, opening a window that allows connecting a local and situational context to a wider societal discourse on sustainability.

\section{References}

Bresnen, M., Edelman, L., Newell, S., Scarborough, H. and Swan, J., 2003. Social practices and the management of knowledge in project environments. International Journal of Project Management 21, 157-166.

Bresnen, M., Goussevskaia, A., Swan, J., 2005. Implementing Change in Construction Project Organizations: Exploring the Interplay between Structure and Agency. Building Research and Information 33, 547-560.

Brown, J., Duguid, P., 2001. Knowledge and Organization: A Social-Practice Perspective. Organization Science 12, 198-213.

Brown, H. S., Vergragt, P., 2008. Bounded socio-technical experiments as agents of systemic change: The case of zero-energy residential building. Technological Forecasting \& Social Change 75, 107-130.

Brown, H. S., Vergragt, P., Green, K., Berchicci, L., 2003. Learning for sustainability transition through bounded socio-technichal experiments in personal mobility. Technology Analysis \& Strategic Management 15, 291-315.

Bryman, A., 2008. Social Research Methods. Oxford University Press, New York, USA.

Cerbof (Centre for Energy and Resource Efficiency in the Built Environment), 2011. Retrieved on 2011-11-17 from www.cerbof.se.

Cole, R., 2011. Editorial special issue: Motivating stakeholders to deliver environmental change. Building Research \& Information 39, 431-435.

Dainty, A., Moore, D., Murray, M., 2006. Communication in construction: Theory and practice. Taylor\&Francis, London, UK.

Dalenbäck, J.-O., Mjörnell, M., 2011. Milparena - a network project for knowledge enhancement regarding energy renovation of multi-family buildings in Sweden. In proceedings of Ökosan 2011 - September 28-30, 2011 - Graz, Austria.

Dubois, A., Gadde, L.-E., 2002. The construction industry as a loosely coupled system: implications for productivity and innovation. Construction Management and Economics 20, 621-631. 
E2Rebuild, 2012. Industrialised energy efficient retrofitting of residential buildings in cold climates. EeB PPP Project Review, July 2011.

Füssel, L., 2005. Introduction, in Füssel, L. (Ed.), Corporate Environmental Governance Perspectives on Organising and Communication. Studentlitteratur, Gothenburg, Sweden, pp.11-24.

Gherardi, S., 2009. Introduction: the critical power of the 'practice lens'. Management Learning 50, 115-128.

Gherardi, S., Nicolini, D., 2000. To transfer is to transform: the circulation of safety knowledge. Organization 7, 329-348.

Glad, W., 2012. Housing renovation and energy systems: the need for social learning. Building Research \& Information 40, 274-289.

Gluch, P., Räisänen, C., 2009. An interactional perspective on environmental communication in construction projects. Building Research \& Information 37, 164-175.

Gluch, P., Räisänen, C., 2012. What tensions obstruct an alignment between project and environmental management practices? Engineering, Construction and Architectural Management 19, 127-140.

Heiskanen, E., Lovio, R., 2010. User - Producer Interaction in Housing Energy Innovations: Energy Innovation as a Communication Challenge. Journal of Industrial Ecology 14, 91-102.

Heiskanen, E., Hyysalo, S., Kotro, T., Repo, P., 2010. Constructing innovative users and userinclusive innovation communities. Technology Analysis \& Strategic Management 22, 495511.

Kamp, L., Smits, R., Andriesse, C., 2004. Notions on learning applied to wind turbine development in the Netherlands and Denmark. Energy Policy 32, 1625-1637.

Kimble, C., Grenier, C., Karine G-P., 2010. Innovation and knowledge sharing across professional boundaries: Political interplay between boundary objects and brokers. International Journal of Information Management 30, 437-444.

Lågan, 2012. LÅGAN - a programme for building having very low energy use. Retrieved on 2012-07-05 from www.lagan.se.

Lave, J., Wenger, E., 1991. Situated Learning: Legitimate Peripheral Participation. Cambridge University Press, Cambridge, U.K.

Loorbach, D., 2010. Transition Management for Sustainable Development: A Prescriptive, Complexity-Based Governance Framework. Governance: An International Journal of Policy, Administration, and Institutions 23, 161-183.

Malmqvist, T., Glaumann, M., Svenfelt, Å., Carlson, P.-O., Erlandsson, M., Andersson, J., Wintzell, H., Finnveden, G., Lindholm, T., Malmström, T.-G, 2011. A Swedish environmental rating tool for buildings. Energy 36, 1893-1899. 
Quist, J., Thissen, W., Vergragt, P., 2011. The impact and spin-off of participatory backcasting: From vision to niche. Technological Forecasting \& Social Change78, 883-897.

Räisänen, C., 1999. The Conference Forum as a System of Genres, Acta Universitatis Gothoburgensis, Göteborg, Sweden.

Räisänen, C., Linde, A., 2004. Technologising Discourse to Standardise Projects in MultiProject Organisations: Hegemony by Consensus? Organization 11, 101-123.

Salkie, R., 1995. Text and discourse analysis. TJ Press Ltd, Padstow, UK.

Stenberg, A.-C., Räisänen, C., 2006. The interpretative flexibility of 'green' in the building sector: diachronic and synchronic perspectives. International Studies of Management \& Organizations 36, 32-54.

Swedish Energy Agency, 2010. Sverige blev nettoimportör av el under 2009. Retrieved on 2010-08-30 from www.energimyndigheten.se.

Swedish National Board of Housing Building and Planning, 2010. Bygga-bo-dialogens kompetensutvecklingsprogram för hållbart Byggande och förvaltande - slutrapport. Boverkets tryckeri, Karlskrona, Sweden.

Teigland, R., Wasko, M., 2003. Integrating knowledge through information trading: Examining the relationship between boundary spanning communication and individual performance. Decision Science 34, 261-286.

Thuvander, L., Gluch, P., Gustafsson, M., Baumann, H., 2011. Twelve years of environmental work in the Swedish construction industry. In proceedings of SB11: World Sustainable Building Conference, 18 - 21 October, 2011 Helsinki, Finland.

Tofield, B., Ingham, M., 2012. Refurbishing Europé: An EU strategy for energy efficiency and climate action led by building refurbishment. Build with Care $(\mathrm{BwC})$ paper.

Toller, S., Wadeskog, A., Finnveden, G., Malmqvist, T., Carlsson, A., 2011. Energy use and Environmental Impacts of the Swedish Building and Real Estate management Sector. Journal of Industrial Ecology 15, 294-404.

Vergragt, P.J., Brown, H. S., 2007. Sustainable mobility: from technological innovation to societal learning. Journal of Cleaner Production 15, 1104-1115.

Wenger, E., 1998. Communities of Practice - Learning, Meaning, and Identity. Cambridge University Press, New York, USA.

Whyte, J., Sexton, M., 2011. Motivations for innovation in the built environment: new directions for research. Building Research \& Information 39, 473-482. 